\title{
NEW TECHNIQUE FOR PRODUCING CREAM LIKE FROM BUFFLOE'S MILK
}

\author{
Shetawy M. El-Said * T.H. Ghanem.** \\ El-Hadidi A.A***
}

\begin{abstract}
A small scale handmixer $35 \mathrm{~W}, 230 \mathrm{~V}$ and $50 \mathrm{~Hz}$ was used for producing cream like from buffloe's milk. Raw milk of $5.5 \%$ fat contents was frozen and then leaved in ambient air to be thawed to previously predetermined temperature to give averages of $10,14,18$ and $22{ }^{\circ} \mathrm{C}$. Three different beating revolution speeds were also studied namely: first, third and fifth speeds i.e. 900, 1030 and 1185 rpm respectively to synthesize the optimum beating speed and processing temperature for cream like production. It was found that $900 \mathrm{rpm}$ has the largest values of fat fraction and separation efficiency for all processing temperatures tested. The optimal velocity that maximize fat globules production in the centrifugal field is $1.6925 \times 10^{-5} \mathrm{~cm} / \mathrm{s}$ with the separation efficiency of $60 \%$ at $14^{\circ} \mathrm{C}$ and $900 \mathrm{rpm}$. Several relationships for fat fraction and separation efficiency were introduced with coefficients of determination ranged between 0.89-0.96 for all revolution speeds and milk processing temperatures tested.

On the other hand skim milk produced can be used for home utilization, children drink, bakery, karich cheese, yogurt production and for patient utilization.
\end{abstract}

\section{ITRODUCTION}

bd El Tawab and Hamdy (1967) mentioned that milk fat density
is $0.936-0.946 \mathrm{~g} / \mathrm{cm}^{3}$ at $15{ }^{\circ} \mathrm{C}$, milting point of $28-33{ }^{\circ} \mathrm{C}$,
freezing point of $19-24 \mathrm{oC}$ and index of refraction $1.409-1.462$. James and Carl (1976) reported that the fat globules exist in emulsion in size ranging from 0.1 to $22 \mu \mathrm{m}$, an average size $2-4 \mu \mathrm{m}$, number of fat globules range $1.5-3 \times 10^{9} / \mathrm{cm}^{3}$ and caloric value of milk fat is $8.79 \mathrm{Cal} / \mathrm{g}$. Fox (1995) mentioned that fat is predominantly present in spherical

*Lect. Agric. Eng. Dept. Faculty of Agric., Al-Azhar Univ.

**Associate Prof. , Agric. Eng. Dept. Faculty of Agric., Al-Azhar Univ.;

*** Associate Prof., Dairy Science Dept. Faculty of Agric., Al-Azhar Univ. 
droplets which range in diameter from less than 0.2 to about $15 \mu \mathrm{m}$. The bulk of fat is in globules 1-8 $\mu \mathrm{m}$. diameter.

Robinson (1992) described the separation of milk fat as a process whereby an essentially fat-free portion(skim milk) is separated from a fat -rich portion. The process is physically, relying on the density difference Between the milk fat in globules and the aqueous phase in which they are dispersed. If milk is allowed to stand, fat rises and the familiar process of creaming is observed with a fat -rich fraction collecting at the surface. The upward gravitational force " $\mathrm{f}_{\mathrm{u}}$ " on fat globule is given by:

$$
F_{u}=4 \pi r^{3} g\left(\rho_{s}-\rho_{f}\right) / 3
$$

Where:

$\mathrm{r}$ : radius of globule $\mu \mathrm{m}$.

$\mathrm{g}:$ acceleration due to gravity $\mathrm{cm} / \mathrm{s}^{2}$.

$\rho_{\mathrm{s}}$ :density of serum (skim milk) $\mathrm{g} / \mathrm{cm}^{3}$.

$\rho_{\mathrm{f}}:$ density of fat globule $\mathrm{g} / \mathrm{cm}^{3}$.

The rize of the globule is inhibited by frictional force $\left(f_{f}\right)$ which is given by stock's law:

$$
\mathrm{f}_{\mathrm{f}}=6 \pi \mu \mathrm{rv}
$$

Where :

$$
\begin{aligned}
& f_{f} \text { : fluid viscosity of serum } \\
& v \text { : velocity of globule }
\end{aligned}
$$

When the fat globule is rising at constant terminal velocity then:

$$
\begin{aligned}
f_{\mathrm{f}} & =\mathrm{F}_{\mathrm{u}} \\
6 \pi \mu \mathrm{rv} & =4 \pi \mathrm{r}^{3} \mathrm{~g}\left(\rho_{\mathrm{s}}-\rho_{\mathrm{f}}\right) / 3 \\
\mathrm{~V} & =2 \mathrm{r}^{2} \mathrm{~g}\left(\rho_{\mathrm{s}}-\rho_{\mathrm{f}}\right) / 9 \mu
\end{aligned}
$$

Thus, the velocity with which a fat globule rise is directly proportional to the square of its radius, the density difference between the globule and the serum and inversely proportional to the viscosity of serum.

Fox(1995)stated that since milk fat has a lower density than plasma, the fat globules rise under the influence of a gravitational field force. As a resultant of buoyancy and friction, the globules attain a constant rising speed"v" which for perfect sphere given by stock's equation :

$$
\mathrm{V}=\mathrm{g}\left(\rho_{\mathrm{s}}-\rho_{\mathrm{f}}\right) \mathrm{d}^{2} / 18 \mu
$$

He also added that, from stock's law, it appear that the major factors affecting rising speed of fat globules are: 
1. The density difference between fat globules and serum.

2. Viscosity of serum.

3. Fat globules diameter.

4. Temperature of milk.

5. Aggregate of fat globules.

Abo El-Naga et al. (1966) studied the clustering of fat globules in cow's and buffalo's milk. They found that cow's milk showed similar good fat globules clustering abilities, but, fat globules from buffalo's milk were poor in clustering ability. By using a microscope, they found no difference in size distribution between the top, middle and bottom regions, but the number of clusters decreased as the number of globules in each cluster increased.

Amer et al. (1976) investigated the effect of heating buffalo's milk on its creaming ability. They found that the creaming power increased by either heating to $100^{\circ} \mathrm{C}$ or by diluting it with water. Ibrahim and El-Abd(1969) studied the effect of heat treatment of milk on its viscosity. They found that buffalo's milk had greater viscosity than cow's milk and the main constituents of milk contributing the viscosity were fat and casein. They found also that heating cow's milk to $60^{\circ} \mathrm{C}$ and buffalo's milk to $70^{\circ} \mathrm{C}$ increased the viscosity.

\section{MATERIALS AND METHODS}

\section{MATERIALS}

1. Fresh buffaloe's was obtained from the herd of Mostorod experimental farm , Faculty of Agriculture Al-Azhar University.

2. Handmixer : Handmixer of $35 \mathrm{~W}, 230 \mathrm{~V}$, and $50 \mathrm{~Hz}$ was used for producing creamlike directly from the buffalo's milk.

3. Aluminum cylindrical can was used for beating process.

4. Beating tools used in the present work are depicted in Fig.(1).

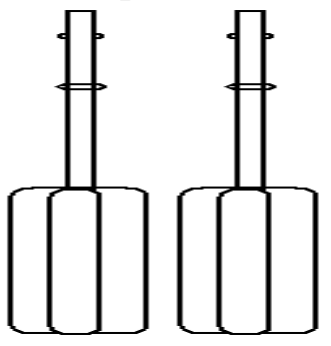


Fig(1) Beating Tools used in the present work.

\section{Measuring instrumentations:}

1- Glass thermometer: For measuring the dry bulb temperatures.

Source of manufacture: China, range: $1-100{ }^{\circ} \mathrm{C}$.

2-Thermocouples:Temperatures were measured using Type $\mathrm{K}$ thermocouples, the output device includes a large 4-digits temperature reading display and electronic circuitry, the specifications of thermocouples are : Model 8528-40 manufactured in U.S.A , Full accuracy of $18-28{ }^{\circ} \mathrm{C}$, useful range : $4-45^{\circ} \mathrm{C}$.

3- Electrical balance: made in Japan, Sartorius type , accuracy $0.0001 \mathrm{~g}$.

\section{METHODS}

1- Row buffalo's milk: Row buffalo's milk 5.5\% fat contents was frozen, and then leaved in ambient air to be thawed to a previously predetermined temperature to give average values of 10,14, 18 and 22 ${ }^{\circ} \mathrm{C}$. Three different beating revolution speeds were studied namely: First, third and fifth speed i.e. 900,1030 and $1185 \mathrm{rpm}$ respectively to synthesize the optimum beating speed and processing temperature for cream like production.

2- Fat content: The standard Gerber method for fat was used as recommended by (Ling 1963).

3- Separation efficiency of fat globules $\eta_{\mathrm{s}} \%$ : The following expression could be used for evaluating the speration efficiency:

$$
\eta_{\mathrm{s}}=\frac{\text { mass of fat in raw milk- mass of fat in skim milk }}{\text { Mass of fat in raw milk }} \% \ldots . .(4)
$$

4- Centrifugal acceleration " $\mathrm{a} " \mathrm{~cm} / \mathrm{s}^{2}$ and velocity of fat globules" $\mathbf{U}_{\mathbf{c}}{ }^{\prime \prime} \mathbf{c m} / \mathbf{s}$ : These variables were evaluated according to Dennis and Paul (1981).They derived an expression for the centrifugal acceleration parameter describing the influence of centrifugal force as follows:

$$
a=r\left(\frac{2 \pi N}{60}\right)^{2}
$$

And for the velocity of spherical particles (fat globules) in the centrifugal force field as:

$$
U_{c}=D^{2} N^{2} r\left(\rho_{p}-\rho_{s}\right) / 1640 \mu
$$


Where:

$\mathrm{N}$ : rotational speed of particle, rpm;

D: fat globule diameter in, $\mu \mathrm{m}$;

$\mathrm{r}$ : distance from the particle to the center of rotation in $\mathrm{cm}$;

$\rho_{\mathrm{p}}$ : density of heavier liquid, $\mathrm{g} / \mathrm{cm}^{3}$;

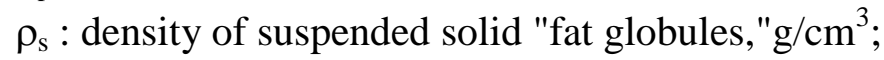

$\mu$ : Viscosity of the suspension, cPoise .

Fat density " $\rho_{\mathrm{f}}$ " was evaluated according to Romeo (1991).He derived the following expression for fat density as affected by its temperature as:

$$
\rho_{\mathrm{f}}=0.92559-0.41757 \mathrm{~T}
$$

The density, viscosity and fat globule diameter of the buffalo's milk used in the present work are cited after Abd El Hameid 2001.

\section{RESULTS AND DISCUSSIONS}

Table(1) shows the effect of average processing temperature of milk on fat fraction " $\mathrm{f}_{\mathrm{f}}$ "\% ,weight of extracted fat " $\mathrm{w}_{\mathrm{f}}$ " $\mathrm{g}$, actual fat weight in cream " $\mathrm{w}_{\mathrm{fa}}$ " $\mathrm{g}$ based on fat fraction and fat density " $\rho_{\mathrm{f}}$ " at three different beating revolution speeds 900, 1030 and $1185 \mathrm{rpm}$. It was found that, although the $\mathrm{w}_{\mathrm{f}}$ has the largest value at $1185 \mathrm{rpm}$, the actual fat weight in cream has not the largest value, due to reduction its fat fraction. Fig. (2) shows that the fat fraction in cream increases as the processing temperature increases from 10 to $16{ }^{\circ} \mathrm{C}$, meanwhile, increasing the average processing temperature of milk to $22^{\circ} \mathrm{C}$ decreases the fat fraction for all studied beating revolution speeds. It is clear that the revolution speed of $900 \mathrm{rpm}$ has the largest values of fat fraction in cream of all tested beating revolution speeds. The optimal experimental value gives $30 \%$ fat fraction in cream at $900 \mathrm{rpm}$ and $14{ }^{\circ} \mathrm{C}$. The following relationships were found to be satisfied for fat fraction $\mathrm{f}_{\mathrm{f}} \%$ as affected by processing temperatures at different beating revolution speeds:

\begin{tabular}{|c|c|c|}
\hline $\begin{array}{c}\text { Beating revolution } \\
\text { speed rpm }\end{array}$ & Satisfied equation & $\mathrm{R}^{2}$ \\
\hline 900 & $\mathrm{f}_{\mathrm{f}}=-0.4219 \mathrm{~T}^{2}+13.575 \mathrm{~T}-80.513$ & 0.89 \\
\hline 1030 & $\mathrm{f}_{\mathrm{f}}=-0.3281 \mathrm{~T}^{2}+10.775 \mathrm{~T}-65.088$ & 0.89 \\
\hline 1185 & $\mathrm{f}_{\mathrm{f}}=-0.2344 \mathrm{~T}^{2}+7.9751 \mathrm{~T}-50.663$ & 0.96 \\
\hline
\end{tabular}


Table(2) shows the effect of average processing milk temperature ${ }^{\circ} \mathrm{C}$ on the separation efficiency $" \eta_{\mathrm{s}} " \%$, centrifugal acceleration $" \mathrm{a} " \mathrm{~cm} / \mathrm{s}^{2}$ and velocity of spherical fat particles in centrifugal force field " $U_{c}$ " at the three different beating revolution speeds tested. It is clear that the centrifugal acceleration is directly affected by revolution speeds. As the revolution speed increases, the centrifugal acceleration increases. The velocity of fat globules is directly affected by the revolution speed as well as the milk processing temperature. Little variations in milk processing temperatures when, the revolution beating speed is constant. As the beating revolution speed increases the velocity of fat globules is also increases. Fig.(3) shows also the effect of processing temperature on the separation efficiency of fats $\%$ at the three different revolution speeds studied. It is clear that the trend of the separation efficiency is approximately similar to that of fat fraction in cream. The optimal velocity that maximize fat globules production in the centrifugal field is $1.6925 \times 10^{-5} \mathrm{~cm} / \mathrm{s}$ with the separation efficiency of $60 \%$ at $14{ }^{\circ} \mathrm{C}$ and 900 $\mathrm{rpm}$. The following relations for the separation efficiency as affected by milk processing temperature and beating revolution speeds were found to be satisfied:

\begin{tabular}{|c|c|c|}
\hline $\begin{array}{c}\text { Beating } \\
\text { revolution speed } \\
\text { rpm }\end{array}$ & Satisfied equation & $\mathrm{R}^{2}$ \\
\hline 900 & $\eta_{\mathrm{s}}=-0.4688 \mathrm{~T}^{2}+16.6 \mathrm{~T}-104.23$ & 0.96 \\
\hline 1030 & $\eta_{\mathrm{s}}=-0.2188 \mathrm{~T}^{2}+7.5 \mathrm{~T}-32.625$ & 0.93 \\
\hline 1185 & $\eta_{\mathrm{s}}=-0.7188 \mathrm{~T}^{2}+24.05 \mathrm{~T}-140.93$ & 0.91 \\
\hline
\end{tabular}

On the other hand skim milk produced can be used for home utilization, children drink, bakery, karich cheese, yogurt production and for patient utilization.

\section{SUMMARY AND CONCLUSION}

A small scale handmixer $35 \mathrm{~W}, 230 \mathrm{~V}$ and $50 \mathrm{~Hz}$ was used for producing cream like raw from buffloe's milk of $5.5 \%$ fat contents. Three different beating revolution speeds were studied namely: first, third and fifth speeds i.e. 900, 1030 and $1185 \mathrm{rpm}$ respectively to synthesize the optimum beating speed and processing temperature for cream like production. From the present work we can concluded that: 
1. The optimal experimental value gives $30 \%$ fat fraction in cream at $900 \mathrm{rpm}$ and $14^{\circ} \mathrm{C}$.

2. The centrifugal acceleration is directly affected by revolution speeds. As the revolution speed increases, the centrifugal acceleration increases.

Table(1) The effect of average processing temperature of milk on fat fraction " $f_{f} " \%$, weight of extracted fat " $w_{f}$ " $g$, actual fat weight in cream " $w_{\mathrm{fa}}$ " $g$ and fat density " $\rho_{\mathrm{f}}$ " at three beating revolution speeds tested.

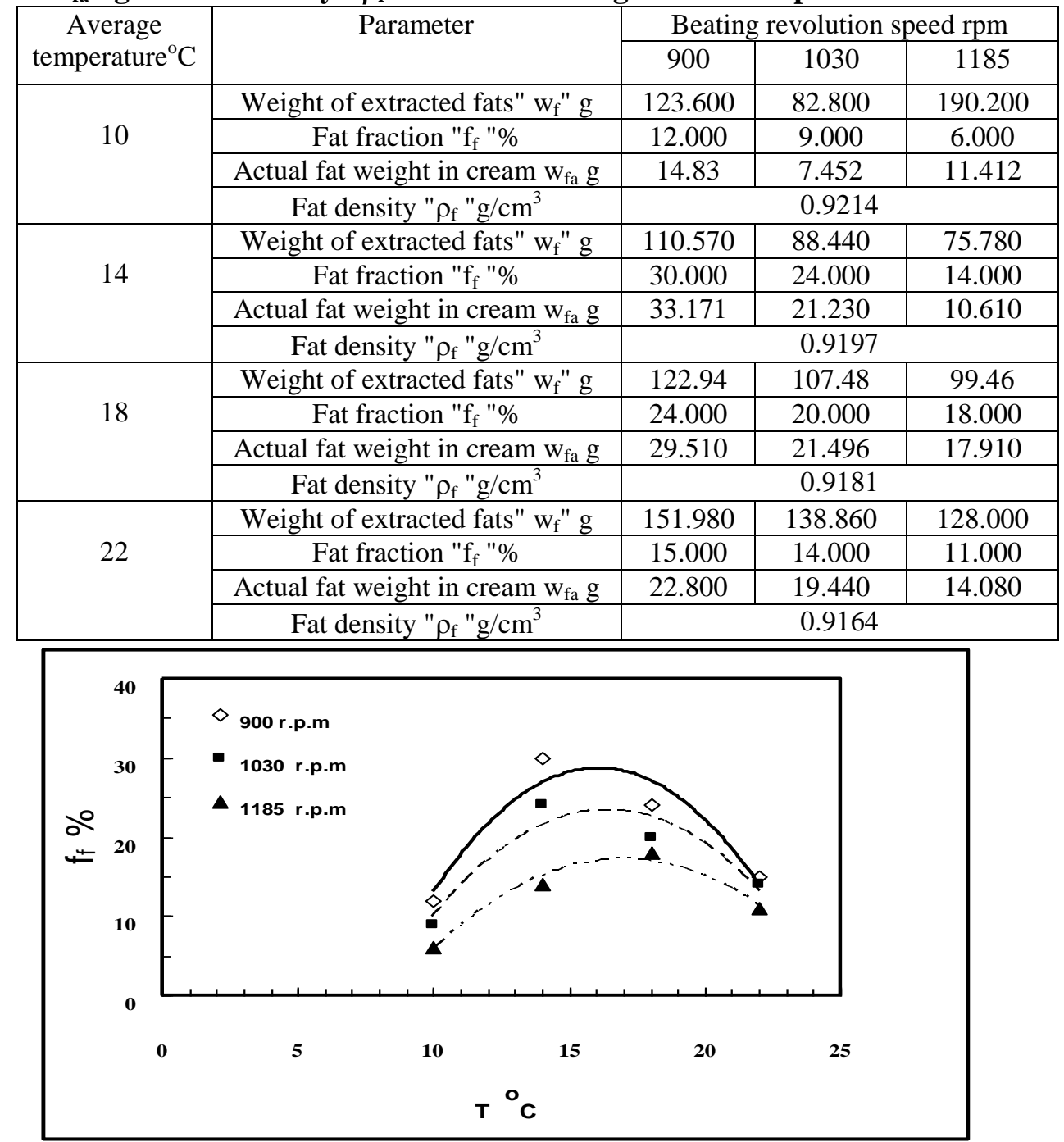

Fig.(2)The effect of the average processing temperature of milk ${ }^{\circ} \mathrm{C}$ on separated fraction of fats in cream $\mathrm{f}_{\mathrm{f}} \%$ at three different beating revolution speeds . 
Table(2) The effect of average processing milk temperature ${ }^{\circ} \mathrm{C}$ on the separation efficiency " $\eta_{s} " \%$, centrifugal acceleration " $\mathrm{a} " \mathrm{~cm} / \mathrm{s}^{2}$ and velocity of spherical fat particles " $U_{c}$ " $\mathrm{cm} / \mathrm{s}$ at milk density, viscosity and globule diameter of $1.025 \mathrm{glcm}^{3}$, $1.68 \mathrm{cPois}$ and $2.7 \mu \mathrm{m}$ for the three studied beating revolution speeds .

\begin{tabular}{|c|c|c|c|c|c|}
\hline \multirow{2}{*}{$\begin{array}{l}\text { Average } \\
\text { teme }{ }^{\circ} \mathrm{C}\end{array}$} & \multirow{2}{*}{ Parameter } & \multicolumn{4}{|c|}{ Beating revolution speed rpm } \\
\hline & & 900 & 1030 & 1185 & St.Dv. of $U_{c}$ \\
\hline \multirow{3}{*}{10} & $\eta_{\mathrm{s}} \%$ & 26.000 & 14.000 & 21.000 & \\
\hline & $\mathrm{U}_{\mathrm{c}} \mathrm{cm} / \mathrm{s}$ & $1.665 \times 10^{-5}$ & $2.181 \times 10^{-5}$ & $2.887 \times 10^{-5}$ & $6.13 \mathrm{E}-06$ \\
\hline & $\mathrm{a} \mathrm{cm} / \mathrm{s}^{2}$ & 66582 & 95878 & 115427 & \\
\hline \multirow{3}{*}{14} & $\eta_{\mathrm{s}} \quad \%$ & 60.000 & 39.000 & 19.000 & \\
\hline & $\mathrm{U}_{\mathrm{c}} \mathrm{cm} / \mathrm{s}$ & $1.6925 \times 10^{-5}$ & $2.2169 \times 10^{-5}$ & $2.9343 \times 10^{-5}$ & $6.23 \mathrm{E}-06$ \\
\hline & a $\mathrm{cm} / \mathrm{s}^{2}$ & 66582 & 95878 & 115427 & \\
\hline \multirow{3}{*}{18} & $\eta_{\mathrm{s}} \quad \%$ & 54.000 & 40.000 & 33.000 & \\
\hline & $\mathrm{U}_{\mathrm{c}} \mathrm{cm} / \mathrm{s}$ & $1.718 \times 10^{-5}$ & $2.2506 \times 10^{-5}$ & $2.9789 \times 10^{-5}$ & $6.33 \mathrm{E}-06$ \\
\hline & $\mathrm{a} \mathrm{cm} / \mathrm{s}^{2}$ & 66582 & 95878 & 115427 & \\
\hline \multirow{4}{*}{22} & $\eta_{\mathrm{s}} \quad \%$ & 42.000 & 35.000 & 26.000 & \\
\hline & $\mathrm{U}_{\mathrm{c}} \mathrm{cm} / \mathrm{s}$ & $1.7456 \times 10^{-5}$ & $2.286 \times 10^{-5}$ & $3.0262 \times 10^{-5}$ & $6.43 \mathrm{E}-06$ \\
\hline & $\mathrm{a} \quad \mathrm{cm} / \mathrm{s}^{2}$ & 66582 & 95878 & 115427 & \\
\hline & St.Dv. of $U_{c}$ & $3.45 \mathrm{E}-07$ & $4.5 \mathrm{E}-07$ & 5.97E-07 & \\
\hline
\end{tabular}

3. The velocity of fat globules is directly affected by the revolution speed and is also affected by the milk processing temperature. Little variations in milk processing temperatures as the revolution beating speed is constant. As the beating revolution speed increases the velocity of fat globules is also increases.

4. The optimal velocity of fat globules in the centrifugal field is $\mathbf{1 . 6 9 2 5}$ $\mathrm{x} 10^{-5} \mathrm{~cm} / \mathrm{s}$ with the separation efficiency of $60 \%$ at $14{ }^{\circ} \mathrm{C}$ and 900 rpm.

5. Several relationships for fat fraction and separation efficiency were introduced with coefficients of determination ranged between 0.89 0.96 for all revolution speeds and milk processing temperatures tested. 


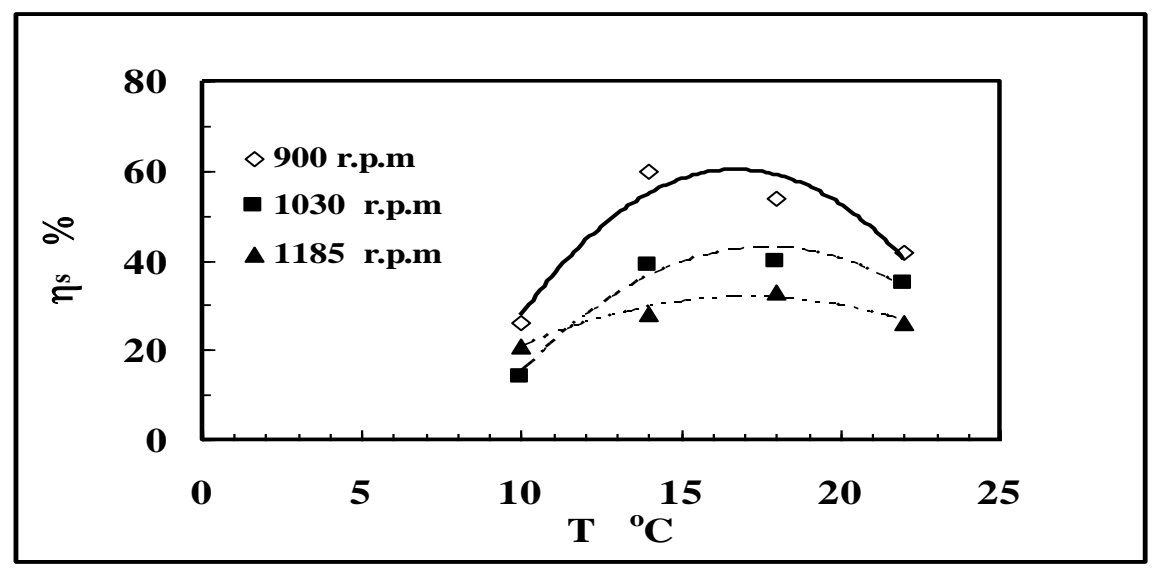

Fig.(3) Effect of average processing temperature ${ }^{\circ} \mathrm{C}$ on the separation efficiency of fat $\eta \mathrm{s} \%$ from the raw buffloe's milk of $5.5 \%$ fat content at the three tested revolution speeds.

\section{REFFRENCES}

Abd El-Tawab and Hamdy 1967.Milk processing technology, p. 11 296297.(Cited after Abd El Hameid El-S.Abd El-H.2001)

Abd El Hameid El-S.Abd El-H.2001.Mechanization of scalded milk cream process. M.sc. Thesis of Ag.Eng. Fuculty ofAgr. Al-Azhar Univ.

Abo El-Naga,I.G.,Sadek,G.M.and El-sokary,A.M.1966. Clustering of fat globules in cow's and buffalo's milk. Creaming ability mechanism and physical arrangement of gobules in gravity cream.Milchwissen schft,21,210-215. (Cited after Abd El Hameid El- S.Abd El-H.2001).

Amer S.N.,Ghita,I.I. and Abdou,S.M.1976.Effect of heating and diluting buffalo's milk and its creaming. Annals. J. of Agr. Sci.,6.

Dennis,R.H. and Paaul, R.S.1981.Food process engineering.AVI Publishing Co.Inc. West-port, Conn. U.S.A . 375-378.

Fox,P.E.1995.Advanced dairy chemistry-2 :Lipids Chapman and Hall, London.

Ibrahim,M.K. and El-Abd,M.M.1969.Viscosity studies, in Bulletin Abrio. Collag. Ciro Univ.XX.No. 1 (1969).

James,W.and Carl,W.1976. Dairy technology and engineering, Wesport,The AVI Comp.Inc : 57-59. (Cited after Abd El Hameid El-S.Abd El-H.2001) 
Ling,E.R.1963.Atext book of dairy chemistry. Vol. II 3 raded. Chapman and Hall Ltd.London.

Robinson,R.K.1992. Modern dairy technology, Chapman and Hall Ltd.London.

Romeo,T.T 1991. Fundamentals of food process engineering. $2^{\text {nd }}$ ed. AVI Publishing Co.Inc.by Van Nostrand Reinhold.233-234.

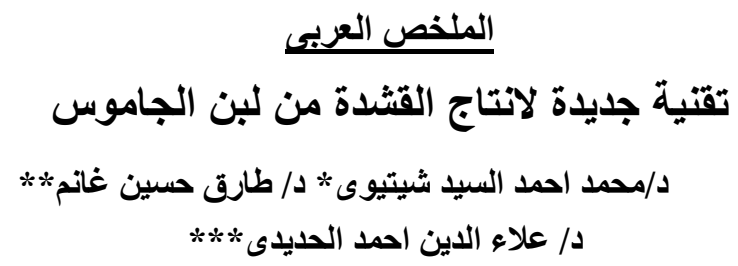

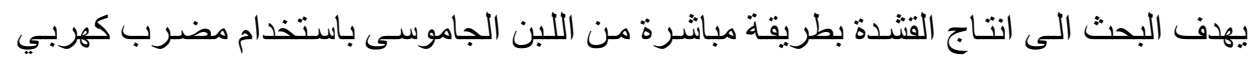

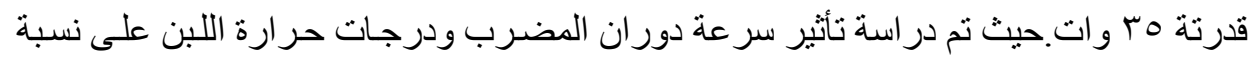

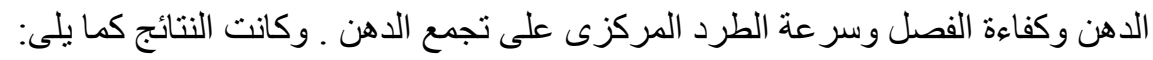

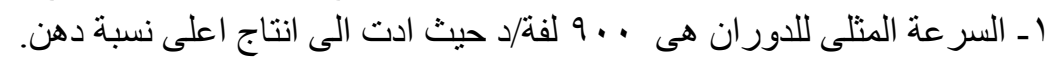

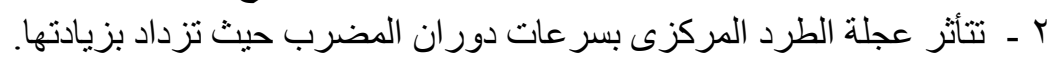

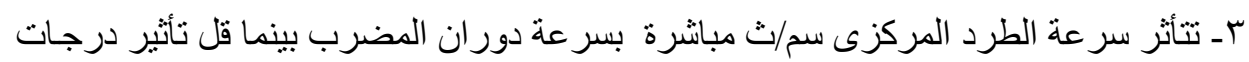

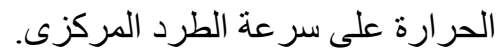

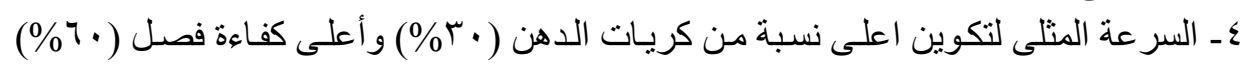

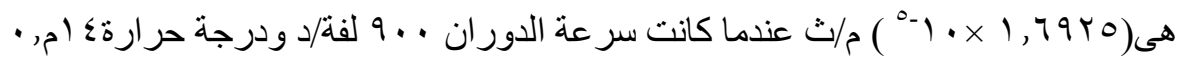

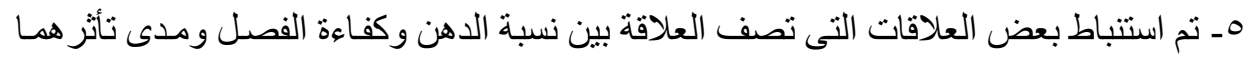

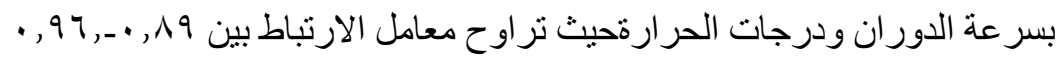

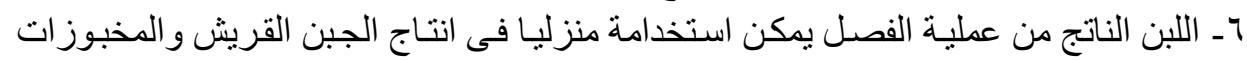

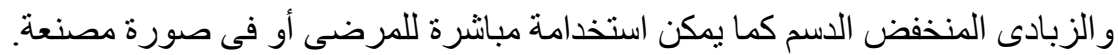

* مدرس الهندسة الزراعية - كلية الزراعة - جامعة الأز هر.

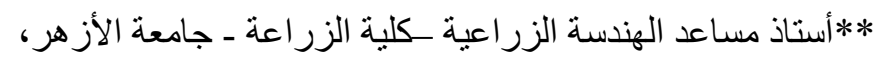

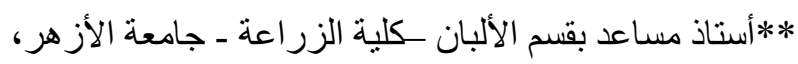

